\title{
A arte, a USP \\ e o devir do MAC
}

TADEU CHIARELLI

A

RECENTE autonomia conquistada pelos Museus da Universidade de São Paulo fez emergir a oportunidade deste Dossiê sobre os museus da USP, ocasião propícia para levantar algumas questões sobre o Museu de Arte Contemporânea da USP que, prestes a completar 50 anos em 2013, e a mudarse para uma nova sede, vivencia a necessidade de repensar publicamente sua história dentro da Universidade para melhor projetar seu devir.

Partindo da questão básica - o que significa ou o que pode significar um museu como o MAC pra uma universidade como a USP? -, este texto objetiva contribuir para esse processo de revisão da história do Museu que até agora tivemos e para o processo de prospecção do MAC que queremos.

Um dado que ajudará a explicar a peculiaridade da situação assumida pelo MAC dentro da USP é lembrar que ele não foi criado em 1963, como fruto de um projeto da própria Universidade, preocupada em possuir um museu de arte contemporânea entendido como mais um centro de excelência dentro do campus, um museu dedicado a selecionar, preservar, estudar e exibir obras de arte contemporânea. Pelo contrário: a USP, naquele ano, ao negociar para si o significativo acervo do antigo Museu de Arte Moderna de São Paulo - constituído por obras de arte brasileiras e internacionais cobrindo as cinco primeiras décadas do século passado -, viu-se de repente detentora de um patrimônio para o qual - e a história das relações do MAC com a USP prova essa afirmação - não estava preparada e nem, de fato, interessada em administrar.

A Universidade adaptou-se como pôde a esse patrimônio, constituindo paliativos para sua preservação e estudo, sem, no entanto, ter criado condições efetivas para que esse patrimônio inicial (hoje muito expandido, graças, sobretudo, aos diretores do MAC e à sua equipe) encontrasse um espaço físico e simbólico digno de si mesmo e da Universidade onde está inserido. ${ }^{1}$

Até dezembro de 2010, o MAC USP - assim como os demais museus da Universidade - não fazia parte do projeto geral da USP, entendida como um centro de produção de conhecimento nas áreas das Ciências e Humanidades. De novo como os demais museus da Universidade, o MAC, até aquela data, estava relegado ao campo da difusão cultural da Universidade. Ou seja: na prática não era reconhecido em sua legítima condição de centro de produção de conhecimento a partir de um universo material e simbólico determinado por sua 
coleção: a produção tradicionalmente ligada à área das artes plásticas (desenho, pintura, gravura, escultura), mas hoje expandida, aberta não apenas às novas tecnologias (fotografia, vídeo, mídias digitais etc.), mas a abordagens artísticas (performance, instalações, publicações etc.) alternativas àquelas já consagradas.

De fato, se tal situação marginal dentro da Universidade foi penosa para todos os museus da USP, parece ter tido consequências mais graves para o MAC, ${ }^{2}$ e isso em razão de determinadas peculiaridades que envolvem a própria maneira como a USP sempre encarou as artes em geral - e as artes visuais em especial - e aquela disciplina que tradicionalmente as tem como objeto: a História da Arte.

A Universidade de São Paulo nunca absorveu em seu projeto o campo da arte como uma área de conhecimento autônomo. Para comprovar tal afirmação, aponto três exemplos: 1. as artes, dentro da USP, surgem apenas em 1971 como um apêndice da Escola de Comunicações Culturais (fundada em 1966 - depois Escola de Comunicações e Artes) que abriga os departamentos ligados à área (Artes Plásticas, Artes Cênicas e Música); 2. a História da Arte, área do conhecimento que, em bases modernas, nasce junto com a Arqueologia durante o século XVIII, até o presente nunca foi reconhecida dentro da USP com dignidade científica suficiente para obter, dentro dos quadros da graduação, um curso específico; ${ }^{3} 3$. o último, mas não menos importante, exemplo é encontrado na própria maneira como o Museu de Arte Contemporânea da USP vem sendo tratado pelas várias gestões reitorais nessas últimas cinco décadas.

Em uma cultura como a brasileira, ainda impregnada por seu passado escravagista, qualquer trabalho em que sobressaia sua dimensão operativa, manual (uma das características tradicionais do trabalho do artista plástico), é entendido como típico de produtores desqualificados socialmente. Nesse sentido, entendese o pouco apreço com que a sociedade encara a produção dos artistas. Para ela, a arte, além de ser trabalho tradicionalmente atribuído a indivíduos "desqualificados", produz objetos creditados como supérfluos. Já para as elites supostamente preocupadas com o desenvolvimento do Brasil e imbuídas de certo verniz, a arte parece não passar de uma espécie de "carga" herdada da tradição erudita ocidental, uma carga que, fundamentalmente desnecessária, atualmente nem mesmo serviria como passatempo, uma vez que teria sido superada pela indústria cultural, mais "preparada" a preencher os espaços de lazer - único território atribuído à arte por essa mesma elite.

Tal posicionamento, creio, explicaria, no geral, o fato de o vocábulo "Artes" estar apenso ao nome da Escola de Comunicações da USP. Para que, afinal, constituir um Instituto voltado para o ensino e produção de artes dentro da Universidade - como foi aventado em alguns momentos dentro da USP -, uma vez que essas atividades, numa concepção deveras discutível, não davam mais conta de preencher as demandas de uma sociedade cada vez mais voltada para o engajamento na produtividade, na eficácia e na obtenção de resultados práticos? Melhor deixá-las à míngua junto a áreas mais "dinâmicas" e inseridas no 
projeto que, balizando a sociedade brasileira como um todo, baliza também a USP.

O mesmo poderia ser dito para explicar o inexplicável, ou seja, a inexistência dentro da USP de um curso de graduação em História da Arte: por que incentivar a formação de jovens em uma área que se nutre expandindo os conhecimentos hauridos em um tipo de produção de cunho supostamente apenas operativo, uma vez que outras modalidades de passatempo demonstram maior eficácia e resultados matematicamente aferíveis?

A sociedade brasileira como um todo e a Universidade de São Paulo em particular ainda não se deram conta de que o universo das artes configura uma área específica do saber e que, ao lado da Ciência, suas várias aplicações, e das Humanidades, deve compor as bases de qualquer centro universitário. E mais: na atualidade dominada pela lógica da produtividade mensurável a todo custo, tem sido a arte - no exterior e no Brasil - um dos raros espaços em que ainda é possível estabelecer uma interpretação crítica a essa mesma lógica, capaz de desvelar/problematizar suas estruturas e ressonâncias nem sempre socialmente benéficas.

Em uma Universidade em que a dimensão crítica trazida pela arte não é de fato reconhecida, como ficaria a situação de seu museu de arte contemporânea? Se os museus da USP ligados a áreas tão respeitadas como a História, a Zoologia, a Arqueologia e Etnologia demoraram tanto a conquistar o reconhecimento oficial da Universidade, seria lícito pensar que o MAC também conquistou sua autonomia por estar a reboque daquelas outras instituições? ${ }^{4}$

Faz quatro anos, a Secretaria de Estado da Cultura do Estado de São Paulo resolveu passar para a USP o complexo arquitetônico onde até então funcionava o antigo Detran de São Paulo, para que a Universidade - após reforma/ recuperação do complexo e construção de um anexo pela Secretaria - alojasse o MAC USP.

Note o leitor que no parágrafo anterior usei a expressão "resolveu passar para a USP", o que significa que a Secretaria, com aquela atitude, não procurou responder a uma demanda da própria Universidade interessada em articular a posse de um edifício de significativo valor estético e histórico que contemplasse, finalmente, a importância do acervo do seu Museu de Arte Contemporânea. A USP apenas reagiu, de forma bastante peculiar, como será visto, a uma demanda feita pela Secretaria.

O que parece ter motivado a Secretaria a realizar tal proposta foi o reconhecimento da importância do acervo do MAC e a necessidade de que o Museu de Arte Contemporânea da USP, naquela nova e grandiosa dependência, fosse absorvido pela lógica que impera nas recentes gestões governamentais do Estado no campo da arte e da cultura: aquela que acredita serem tais instituições aparelhos ligados aos serviços de lazer e turismo. 
Por mais urgente que seja discutir esses objetivos da Secretaria em relação ao MAC USP, é certo não caber aqui debatê-los, e sim comentar sobre como a USP, como um todo, recebeu aquela proposta.

A despeito de certo mal-estar e incredulidade iniciais por parte de membros do próprio Museu, a proposta da Secretaria foi aceita de maneira passiva pela USP como um todo, não tendo ocorrido discussões internas mais aprofundadas que ponderassem sobre como a Universidade encarava tal proposição e o que estava em jogo aceitá-la.

No âmbito da estrutura administrativa da USP, o que deve ter contribuído para o aceite da proposta, pode-se especular, é que, para a direção da Universidade, a retirada do MAC do campus da USP nada significava, a não ser, talvez, a ideia - aliás, equivocada - de que os imóveis que hoje o Museu detém no campus seriam desocupados, liberando-os para a resolução de demandas de ocupação consideradas prioritárias.

Se a reação da direção da USP pode ser qualificada como um misto de desinteresse e alívio, a comunidade uspiana em geral respaldou tal proposta com a mesma passividade. Apesar do Seminário "Pensando o novo MAC", promovido pela própria instituição, que discutiu aspectos específicos de gestão de museus, ${ }^{5}$ em nenhum momento foi debatido publicamente o que significava a retirada do Museu da Cidade Universitária, após mais de três décadas que parte significativa do MAC deixou seu alojamento primitivo no terceiro andar do edifício da Fundação Bienal de São Paulo rumo ao campus do Butantã. ${ }^{6}$

Como corolário dessa falta de discussão também não se levantou um dado que a todos preocupa: a paulatina mas significativa perda de ressonância das ações do MAC após aquela transferência que teve início em 1983. A "volta” do MAC para o Ibirapuera, quando ele passasse a ocupar as antigas dependências do Detran e mais o novo anexo, significaria para o Museu reassumir o protagonismo por ele já assumido dentre os centros de arte e cultura mais significativos do país, ou tal "retorno" significaria, de fato, deixá-lo à mercê dos interesses do mercado de exposições-produtos de mídia?

Não se conhece até o momento nenhuma reunião, seminário, nenhum documento que ateste ter havido, por parte da comunidade universitária, qualquer interesse efetivo sobre o devir do MAC na nova sede, e do papel que esse museu universitário de arte contemporânea, pertencente à Universidade de São Paulo, passaria a cumprir, ocupando um complexo arquitetônico imantado de interesse histórico e estético, de autoria de Oscar Niemeyer, situado no Parque Ibirapuera. Também não se discutiu publicamente se o fato de o MAC ocupar aquele novo complexo - passando a fazer parte do polo de instituições museológicas voltado para o objetivo de conferir à cidade de São Paulo, atrativos de lazer e turismo ${ }^{7}-$ poderia entrar em conflito com os propósitos universitários da instituição.

A indiferença com que foi tratada a agora iminente transferência do MAC USP para o antigo edifício do antigo Detran de São Paulo ratifica toda a história 
de 50 anos do Museu, em suas relações com a USP. Afinal, o que pode, de fato, significar um museu universitário de arte contemporânea em uma Universidade em que as artes - e as artes visuais em particular - sempre foram tratadas como apêndices virtualmente dispensáveis dentro de uma filosofia em que o pragmatismo impera?

A atual direção do MAC, em acordo com as diretrizes reitorais estabelecidas pelo Prof. João Grandino Rodas para os museus da Universidade, percebe positivamente a transferência de parte significativa do MAC USP para o adaptado edifício do antigo Detran, por entender que o MAC, no campus do Butantã, de fato não consegue dar conta dos desafios que hoje se apresentam a qualquer instituição museológica ligada às artes visuais e que esteja fora do circuito de arte ainda pouco expandido da cidade.

O MAC entende que a concentração de suas atividades em um espaço imantado pelas qualidades arquitetônicas do antigo Detran, às margens do Parque Ibirapuera, pode contribuir para que a instituição recupere o protagonismo que ela possuiu durante décadas na cidade. No entanto, nós todos sabemos que não basta a ocupação de um dos complexos arquitetônicos modernistas mais belos de São Paulo para que o MAC renasça como um verdadeiro polo universitário de arte atual.

Para que essa transformação tenha chances concretas de êxito, faz-se urgente que a Universidade de São Paulo desperte de seu torpor ou simples indiferença ao devir do MAC USP, e assuma de vez o que é patente para todos: não é o MAC quem está indo para aquele complexo, é a Universidade de São Paulo quem, por intermédio do seu Museu de Arte Contemporânea, irá ocupá-lo.

O que a USP deve entender é que, caso se torne consciente desse imenso passo, ela poderá tornar-se a única Universidade em todo o Hemisfério Sul a possuir um museu que, pautado por um acervo invejado internacionalmente, estabelecerá novos patamares críticos para as ações que atualmente regem as áreas de curadoria, museografia e de educação/formação de público em museus de arte. Porém, se tal consciência não emergir, a USP colocará em risco sua reputação nas áreas da arte e da cultura, com imprevisíveis consequências nos planos local e internacional.

Para que tal consciência se consolide de forma positiva, é fundamental a implantação de uma política que envolva toda a comunidade uspiana que deve estar preparada para esse imenso passo que dará a Universidade, quando o MAC for transferido em grande parte para o antigo Detran. E para que estudantes, funcionários e docentes se envolvam, sintam-se finalmente como os responsáveis diretos desse patrimônio, é importante que eles de fato conheçam o MAC e entendam sua importância, entendam o que pode significar um museu de arte atual, tanto para a Universidade quanto para toda a sociedade brasileira. 

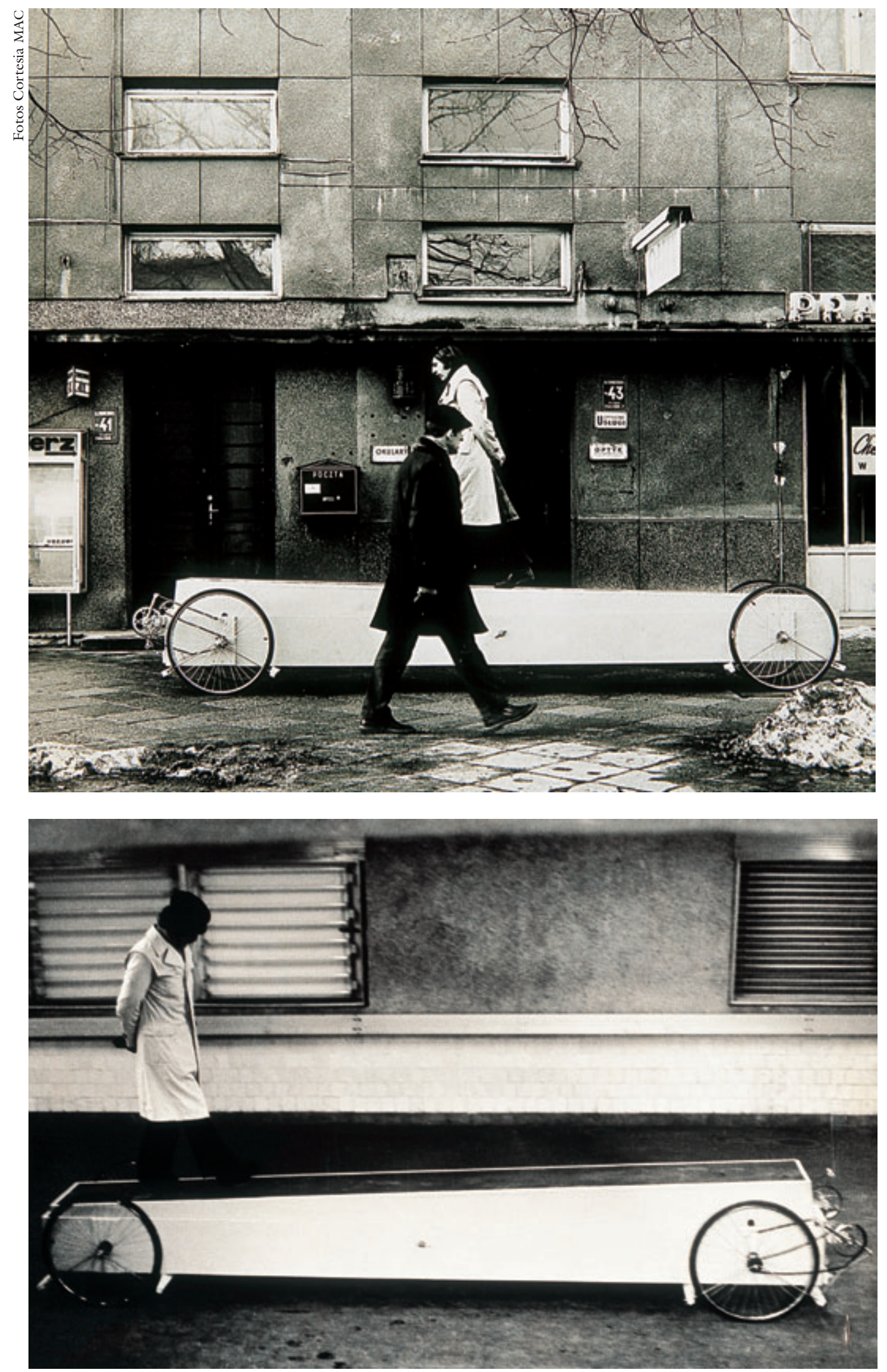


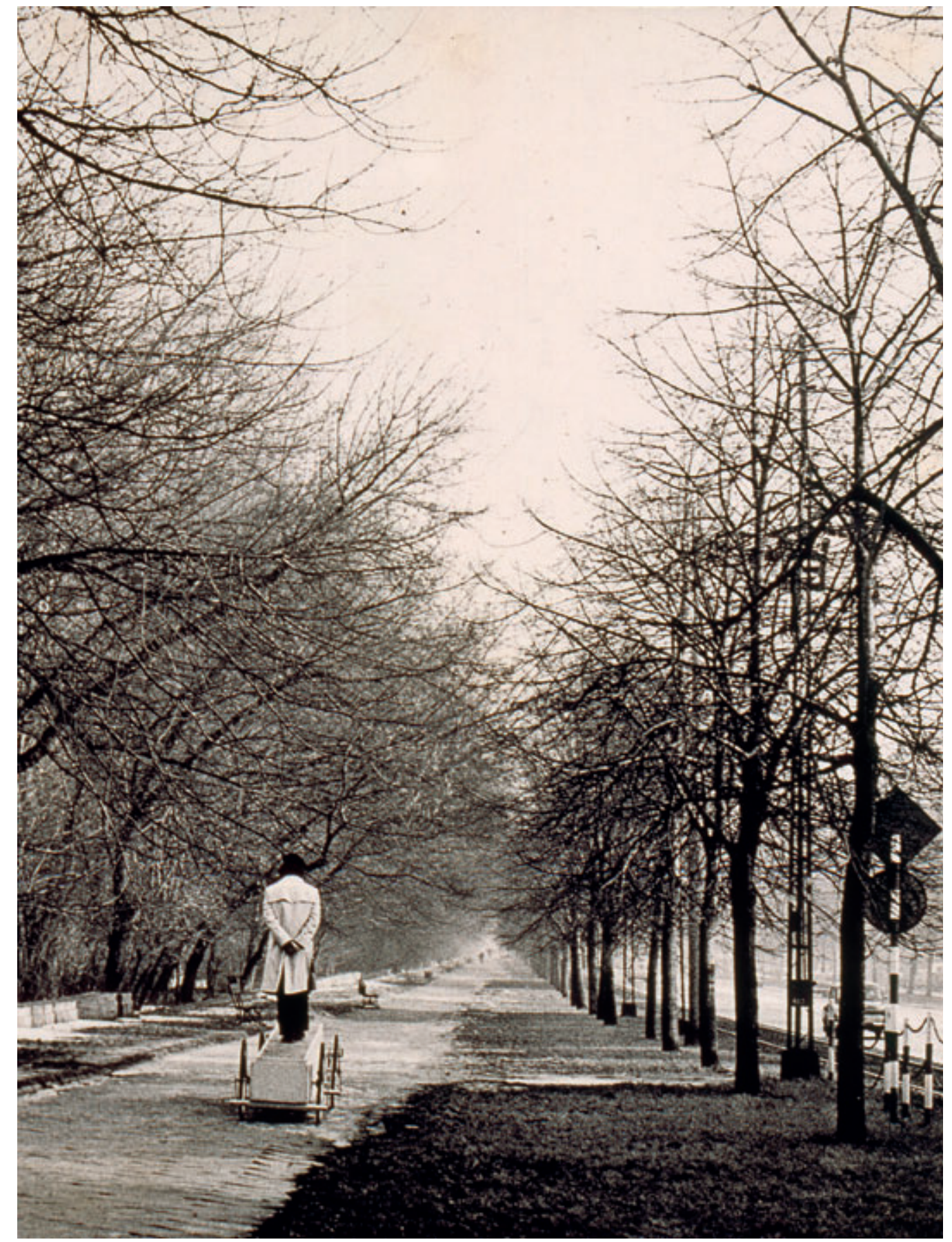

Krzysztof Wodiczko, Veículo, 1973.

O estudioso alemão Boris Groys (2008, p.184ss.), no ensaio “El museo en la era de los médios", argumenta sobre a importância dos museus de arte nos dias de hoje, período de supremacia dos meios de comunicação. Mesmo correndo o risco de simplificar suas ideias, creio que trazê-las para esta discussão ajudará no entendimento do que pode significar um museu de arte como o MAC para uma universidade como a USP. 
Groys inicia o artigo historiando não apenas a trajetória do museu como instituição que encarnou e definiu o gosto dominante, durante os séculos XIX e XX, como também as investidas contra o próprio museu, recorrentes desde as vanguardas do início do século passado até os dias atuais. O autor informa, no entanto, que as atuais investidas não possuem as mesmas características daquelas das vanguardas, e isso porque "hoje o museu perdeu sua função normativa. Em nosso tempo, os meios de comunicação ditam a norma estética: faz tempo que substituíram o museu nessa sua função social central" (ibidem, p.185). ${ }^{8}$

Groys também sublinha que a mídia insiste em apresentar o museu como espaço em que iniciados decidem o que é e o que não é arte a partir de critérios supostamente herméticos e que, no fundo, não interessam a ninguém. Daí as perguntas: "Por que alguém deve decidir o que é arte e o que não é? Por que cada um não pode decidir por si mesmo..., sem nenhuma tutela...? Por que a arte não pode ser legitimada no mercado midiático aberto - como qualquer outro produto?" (ibidem, p.187).

Todos que trabalham em museus de arte contemporânea sabem que essas perguntas são bastante recorrentes, quer quando acompanhamos visitantes às exposições, quer nos previews e reviews de jornais. Nós do MAC USP estamos acostumados a recebê-las, acompanhadas, quase sempre, de um desdém que tende a limitar qualquer espécie de argumentação. Mas, voltando ao texto de Groys, a certa altura ele estabelece as diferenças que os meios de comunicação enfatizam existir entre eles e o museu. Se esse último - normativo, didático e autoritário, segundo os meios de comunicação - busca impor seu ponto de vista, a mídia, por sua vez, não tenta instituir nenhum paradigma, estando, supostamente, preocupada em oferecer ao público apenas aquilo "que as pessoas gostam". Para o autor, essa visão que os meios de comunicação teriam de si mesmos não se sustenta pelo fato de que o novo, ou o atual, é mostrado por eles como um valor ao qual o espectador tem seu gosto submetido:

Portanto, se, por um lado, as mídias fingem satisfazer o gosto existente, por outro fazem publicidade, tanto direta quanto indireta, para revisar esse gosto e ajustá-lo ao espírito da época. Assim, de nenhum modo se pode dizer que o consumidor no mercado das mídias recebe para ver ou ouvir somente o que ele "realmente gosta" - sem nenhuma tutela. Pelo contrário, a cada passo ele é instruído e informado sobre o que corresponde - e o que não - ao espírito da época presente. (ibidem, p.191)

Para Groys, ninguém poderia se inteirar, por intermédio dos meios de comunicação, sobre o que é o mais atual da atualidade, e isso por uma simples razão:

o mercado global das mídias não tem memória histórica que lhe permita comparar o passado e o presente e desse modo estabelecer o que no presente é realmente novo e genuinamente atual. No mercado das mídias, a velha oferta é substituída continuamente por uma nova oferta. Assim, não se pode comparar o que se oferece hoje com o que foi oferecido antes [...]. Por isso, no mercado das mídias, temos a sensação de estarmos permanentemente ante o novo e, ao mesmo tempo, a sensação de observarmos só o sempre igual. (ibidem, p.191-2) 
Explicitando as diferenças entre as lógicas dos meios de comunicação de massa e o museu de arte, Groys chama a atenção para o fato de que o museu apresenta ao espectador "essa possibilidade de efetuar uma distinção entre velho e novo - e de comprovar criticamente com seus próprios olhos as pretensões de ser novo, atual e pioneiro que são apresentadas pelos meios de comunicação" (ibidem, p.193). Para o autor, em um período em que, por influência dos meios de comunicação de massa, vivemos como que em um presente contínuo, apenas um museu de arte atual nos oferece um espaço de comparação entre passado e presente, possibilitando a manutenção de uma dimensão crítica, tendente a perder-se irremediavelmente, caso essa instituição seja suprimida ou deixada morrer à míngua sob o tsunami estético ideológico dos meios de comunicação de massa. Reiterando seus últimos argumentos, Groys (2008, p.197-8) finaliza o artigo da seguinte maneira:

Porque o museu, diferentemente dos meios de massa, tem à sua disposição meios e possibilidades de tornar-se um lugar de um discurso crítico. E mais: o museu é, nas condições da cultura de hoje, praticamente o único lugar em que podemos nos distanciar do nosso próprio presente, comparando-o com outros tempos. E assim o museu é especialmente apropriado para analisar e comprovar de maneira crítica as pretensões do espírito da época determinado pelos meios de comunicação de massa.

A partir dessa síntese do pensamento do teórico alemão, é importante reforçar uma questão: a oposição entre o novo entendido como mercadoria pela mídia e o caráter relativo do novo, tal como é apresentado pelo o museu de arte, não deve significar que um museu de arte contemporânea só possa fazer a crítica histórica do novo no âmbito da produção artística que exibe.

Embora Groys não explicite, parece claro que, a partir da percepção do atual dentro de um quadro mais amplo de tempo (oferecido pelas exposições no museu), é possível estabelecer discussões que, partindo de certos pressupostos estéticos e/ou artísticos presentes nas obras expostas, transcendam esses limites iniciais, produzindo condições para ampliação da percepção histórica e crítica do período circunscrito pela exibição.

Um museu de arte contemporânea como o MAC USP, portanto, ao exibir justapostos ou contrapostos, obras e/ou documentos de ações artísticas, desde o início do século XX até a atualidade, torna-se um centro fundamental para que o público possa pensar em si mesmo e na coletividade a que pertence dentro de patamares que os meios de comunicação - assim como muitas áreas universitárias - não lhe oferecem ou sonegam.

Nós todos sabemos que o MAC USP, pela riqueza e representatividade de seu acervo, pode instituir-se como um polo de apreensão e discussão das principais questões que abalaram a sociedade brasileira e internacional no último século e na primeira década deste.

Refletir criticamente sobre o legado que nos deixaram os vários "moder- 
nismos" e suas diversas "superações", que marcaram o século anterior, colocando-os em franco confronto com a produção dos dias atuais, é um dos desafios que o MAC USP quer assumir, e que sabe poder assumir, desde que lhe sejam fornecidas as condições concretas para fazề-lo: continuidade das condições para preservação e estudo do acervo existente; ampliação da equipe para levar adiante tais obrigações; condições para a ampliação do acervo; ampliação do corpo de arte-educadores etc.

Se a comunidade uspiana também estiver comprometida com essa estratégia de transformar o MAC USP, em sua nova sede, em um polo de conscientização produtiva e crítica das questões que tocam a nossa contemporaneidade tão problemática, ele conseguirá reverter a situação do debate sobre arte e cultura na USP, bastante obstruído nos últimos anos. Caso contrário, ele apenas irá acelerar a total subordinação desse mesmo debate à lógica do mercado de bens culturais que é, em tese, a própria negação do conceito de museu como o MAC e de uma Universidade como a nossa.

\section{Notas}

1 Na sequência, comentarei a proposta de transferência do complexo arquitetônico onde funcionava o antigo Detran de São Paulo, feita em 2007, pela Secretaria de Estado da Cultura do Estado de São Paulo à USP, para que a Universidade ali implantasse parte significativa do acervo e das atividades do MAC.

2 O Museu Paulista (MP), instituição centenária e, portanto, anterior à própria criação da USP, goza de importante legitimidade junto à população de São Paulo, fincada sobretudo na sua interpretação da formação da sociedade brasileira, vista, até poucos anos atrás pelo Museu, apenas pela óptica de membros da elite paulistana - aquela mesma que ajudou a criar essa Universidade. Em termos simbólicos, o MP confunde-se com São Paulo e, assim, confunde-se com a própria USP. Nesse sentido, por mais árduas que tenham sido as dificuldades passadas pelo Museu desde que de fato se uniu à Universidade, elas tenderam a ser superadas sempre de maneira positiva; com origem também centenária, o Museu de Zoologia (MZUSP) é integrado à USP no limiar dos anos 1970, após uma trajetória (em parte próxima àquela do MP) em que havia adquirido reconhecimento em sua área de atuação. Se, por um lado, como as demais instituições museológicas da USP, o MZUSP atua com dificuldade, goza, por outro, de um grande prestígio junto à comunidade universitária não apenas pela excelência de sua coleção e o trabalho de seus profissionais, mas também por pertencer a uma das áreas mais caras à USP: as Ciências Biológicas; o Museu de Arqueologia e Etnologia, por sua vez, apesar de, como o MAC, não possuir até hoje uma sede que faça justiça à excelência de sua coleção e ao trabalho ali realizado a partir dessa, possui pelo menos o respeito que a Universidade devota às duas áreas em que atua: Arqueologia e Etnologia, dois ramos significativos e reconhecidos pela tradição como significativos e necessários a qualquer instituição universitária que se preze.

3 Tal situação ocorre a despeito tanto do empenho histórico de vários profissionais uspianos, no sentido de reverter esse quadro, quanto da posição lateral que a USP corre o risco de começar a ocupar dentro dessa área, uma vez que outras Universidades brasi- 
leiras vêm instituindo suas graduações em História da Arte já faz certo tempo. Sobre a situação dessa disciplina dentro da USP, consultar, entre outros, Zanini (1983, 1994).

4 Aos interessados em conhecer mais dados sobre as difíceis relações entre a USP e as artes, consultar, entre outros, Amaral (2010, p.112-26) e Zanini (1986, p.32).

5 O Seminário "Pensando o novo MAC" foi promovido em cinco etapas, durante os anos de 2007 e 2009: "Economia e cultura: novos paradigmas em gestão de museus" (seminário interno), dia 17 de dezembro de 2007; "Arquitetura e segurança em museus", dia 28 de março de 2008; "A pesquisa e a curadoria nos museus e o sistema de terceirização da produção cultural", dia 13 de agosto de 2008; "Arquivos de documentação em arte", dia 23 de outubro de 2008; e "Conservação em museu de arte", dia 11 de novembro de 2009.

6 É importante esclarecer que a metade do terceiro andar do edifício ocupado pela Fundação Bienal de São Paulo, no Parque Ibirapuera, ainda é ocupada pelo MAC USP, com parte de seu acervo, área de exposição e outros serviços fundamentais para seu pleno funcionamento.

7 Ao se transferir para o complexo arquitetônico ampliado do antigo Detran, o MAC USP fará parte de um conjunto de instituições voltados para a promoção da arte e a cultura, como a Fundação Bienal de São Paulo, o Museu de Arte Moderna de São Paulo, o Museu Afro-Brasileiro, entre outras.

8 Portanto, seguindo o pensamento de Groys, no que tange às diferenças entre a negação do museu durante o período das vanguardas e o período atual, o dado principal a se destacar é que, na atualidade dominada pela imposição do gosto veiculado pelos meios de comunicação, ser contra o museu não é lutar para a implantação do "novo" - atitude típica das vanguardas do século XX - mas, pelo contrário, fomentar a estabilização totalizadora do gosto dominante dos meios de comunicação.

\section{Referências}

AMARAL, A. Um depoimento: três experiências de trabalho. In: I SEMINÁRIO INTERNACIONAL. ARQUIVOS DE MUSEUS E PESQUISA. Org. Ana G. Magalhães. São Paulo, 9-10 nov. 2009. MAC-USP, 2010. p.112-26.

GROYS, B. El museo en la era de los médios. In: Obra de arte total Stalin. Topologia del arte. Seleção de textos e trad. Desiderio Navarro. La Habana: Centro TeóricoCultural Critérios, 2008.

ZANINI, W. As antigas disciplinas cinderelas da USP. Comunicações e Artes, São Paulo, v.12, p.165-70, 1983.

. A Universidade e as artes. O Estado de S. Paulo, São Paulo, 19 set. 1986. p.32. . Arte e história da arte. Estudos Avançados, São Paulo, v.8, n.22, p.487-9, set./ dez. 1994.

RESUMO - O texto visa refletir sobre o Museu de Arte Contemporânea da USP, sua história e perspectivas, no quadro geral da Universidade de São Paulo em suas relações com as artes visuais. 
PALAVRAS-CHAVE: Museu de Arte contemporânea da USP, Universidade de São Paulo, Artes visuais.

ABSTRACT - The text aims to reflect on the Museu de Arte Contemporânea de São Paulo, its history and prospects, within the general framework of the Universidade de São Paulo in its relation to the visual arts.

KErWORDS: Museu de Arte Contemporânea USP; Universidade de São Paulo, Visual arts.

Tadeu Chiarelli é diretor do Museu de Arte Contemporânea. @ - tchiarelli@uol.com.br Recebido em 19.8.2011 e aceito em 15.9.2011. 